\title{
Application of Eco-Friendly Cutting Fluids Through Small Quantity Lubrication Technique: A Study
}

\author{
Amrit Pal ${ }^{1}$, Sukhpal Singh Chatha ${ }^{2}$ and Hazoor Singh Sidhu ${ }^{3}$ \\ ${ }^{1}$ GZS Campus College of Engineering and Technology, Bathinda, Punjab, India \\ ${ }^{2 \& 3}$ Yadavindra College of Engineering, Punjabi University Guru Kashi Campus, Talwandi Sabo, Punjab, India \\ E-Mail: amritpaul123@gmail.com
}

\begin{abstract}
Owing to environmental concerns and growing regulations over contamination and pollution, the demand for renewable and biodegradable cutting fluids is rising. The aim of this paper is to review the eco-friendly and user-friendly minimum quantity lubrication (MQL) technique using vegetable-based oil and solid lubricant in different machining processes. It has been reported in various literature that the minimum quantity lubrication (MQL) method using vegetable oil-based cutting fluid shows superior performance as compared to dry and wet machining. The major benefits of MQL are reduction of consumption of cutting fluid, cost saving, reduction of impact to the environment and improved overall performances in cutting operation and the surface quality. To achieve improved thermal conductivity researchers focused attention on nano fluids. Nano fluids are nano-metered sized colloidal suspensions in the base fluid like water, oil, glycol, etc. The application of nano fluid controls the tool wear by reducing the temperature. Impingement of the nanoparticles with high pressure in MQL enables entry of nanoparticles at the tool chip interface. Thus it reduces the coefficient of friction and improves machining performance significantly.
\end{abstract}

Keywords: MQL, Environment, Vegetable oil, Nanofluid

\section{INTRODUCTION}

Machining processes are widely used to manufacture components that require great accuracy and/or high surface quality finish. Furthermore, machining is a process that can provide low costs to a certain number of parts. However, to obtain these advantages it is necessary to ensure that the set up (machine, tool, cooling, etc.) is in perfect order (Lauro et al., 2014). Metal Working Fluids are widely employed in machining operations to perform three main functions: lubrication, cooling, and chip transport from the cutting zone. In addition, they may perform secondary functions such as providing temporary protection against oxidation and corrosion (Jayal et al., 2007).Today's there are several types of metal cutting fluids (MCFs) that can be extensively classified as straight fluids, petrochemical, synthetic, semisynthetic fluids, soluble fluidsand vegetable based cutting fluids (VBCFs) (Ozcelik et al., 2011). In the absence of adequate lubrication, friction between the tool and work piece in machining operation results in high cutting temperatures and tool wear; hence, lubrication is critical (Rao and Krishna, 2008). Excessive heat and consequently wear formation are the most important factors affecting performance and productivity of metal cutting operations. In addition, cutting fluids help to provide a uniform temperature field inside the workpiece and machine tool, and help to meet specified tolerances (Weinert et al., 2004).

On the other hand, the cutting fluids have many detrimental effects. Many of the fluids, which are used to lubricate metal forming and machining, contain environmentally harmful or potentially damaging chemical constituents. These fluids are difficult to dispose and expensive torecycle and can cause skin and lung disease to the operators and air pollution. Also the increasingly stricter environmental regulations and their enforcement are eliminating much of the flexibility in the use of cutting fluids. The costs associated with the use of cutting fluids is estimated to be several billion \$/year. Consequently, elimination on the use of cutting fluids, if possible, can be a significant economic incentive (Thakur et al., 2009). As part of an environmental strategy, many manufacturing sites are shifting to dry and semi-dry machining processes. Minimizing the use of cutting fluid also leads to economic benefits, as cutting fluids can account for a significant portion (up to 20\%) of machining costs. All costs involved with cutting fluids (purchasing, recycling, chip drying, etc.) represent 7.5-17\% of the manufacturing costs of a part, which in many cases is even higher than tool costs (Braga et al., 2002).

Hence, the increasing consciousness for green manufacturing globally and consumer focus on environmentally friendly products have put increased pressure on industries to minimize the use of cutting fluids. Any attempt to minimize or avoid the use of coolant can only be addressed by replacing the functions normally meant for the coolants with other methods (Lawal et., 2013). Therefore, an alternative to conventional cutting fluids techniques such as high pressure coolants (HPC), cryogenic cooling, solid lubricants, air/gas/vapour coolant and minimum quantity lubrication (MQL) or near drymachining (NDM) have been reported by different researchers to have addressed the shortcoming of conventional cutting fluid application.

MQL is one of the promising techniques adopted by researchers (Sayuti et al., 2013). The encouraging results include significant reduction in tool wear and surface roughness by MQL obtained as a result of lowered temperature in the cutting zone and favorable changes in the chip-tool and work-tool interactions (Diaz et al., 2010). The 
reduction of tool wear, surface roughness and improving dimensional accuracy was successfully conducted using clean machining processes with minimum quantity lubricant (MQL). MQL shows superior performance compared to dry and wet machining. However, the usage of MQL in conjunction with a nano-lubrication system would be a noteworthy advantage to the manufacturing process due to its effect on product quality (Itoigawa et al., 2007). The aim of the present work is to review the effect of Minimum quantity lubrication (MQL) using different nanofluids and conventional cutting fluids in different machining operations.

\section{MINIMUM QUANTITY LUBRICATION (MQL) TECHNIQUE}

MQL is one of the promising techniques adopted by researchers. The encouraging results include significant reduction in tool wear and surface roughness by MQL obtained as a result of lowered temperature in the cutting zone and favourable changes in the chip-tool and work-tool interactions (Sayuti et al., 2014). Minimum quantity of lubrication refers to the use of cutting fluids of only a minute amount-typically of a flow rate of $50-500 \mathrm{ml} / \mathrm{h}$ which is about three to four orders of magnitude lower than the amount commonly used in flooded condition (Dhar et al., 2006). Minimum quantity of lubrication, also known as near dry machining (NDM), refers to the use of cutting fluids in tiny quantities, which is only about ten-thousandth of the amount of cutting fluid used in flood-cooled machining (Li and Chou, 2010). The schematic view of the MQL setup is shown in Fig. 2.

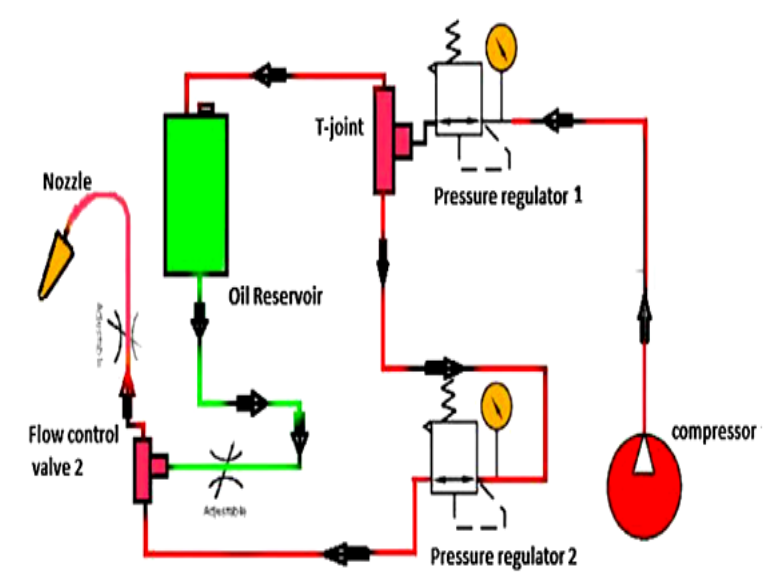

Flow control valve 1

Fig. 2 Schematic view of MQL setup (Sharma and Sidhu, 2014)

In this technique, the chips are released in a practically dry condition, thus avoiding cutting fluid recycling costs. The lubricating function in MQL technique is ensured by the oil and the cooling function is provided mainly by the compressed air. This small amount of fluid suffices to reduce friction in cutting by diminishing the tendency of adhesion in materials with such characteristics (Rabiei et al., 2015 lubricant). A minimum quantity lubrication
(MQL) method is considered as the suitable alternative for precisely delivering the and/or coolant and meeting the requirements of being environmental friendly. However, in dry cutting operations, some problems do appear. The friction and adhesion between the chip and tool tends to be greater, which causes higher temperatures, generating excessive tool wear (Vazquez et al., 2015).

Dhar et al., 2006 investigated the effect of minimum quantity lubrication (MQL) on tool wear and surface roughness in turning AISI-4340 steel at industrial speed feed condition by using uncoated carbide insert (SNMM 120408) tool. The process parameters used were cutting velocity $(110 \mathrm{~m} / \mathrm{min})$, feed rate $(0.16 \mathrm{~mm} / \mathrm{rev})$ and depth of cut $(1.5 \mathrm{~mm})$. The objective of research was to compare the performance of MQL with dry and wet machining. It was observed that the cutting performance of MQL machining is better than that of wet and dry machining. MQL provides the benefits mainly by reducing the cutting temperature, which improves the chip-tool interaction and maintains sharpness of the cutting edges. In another study Li and Chou, 2010 investigated the performance of minimum quantity lubrication (MQL) technique in near micro milling with respect to dry cutting on the basis of tool wear, surface roughness and burr formation. It was observed that the reductions of tool flank wear lengths in MQL cutting compared to dry cutting are about $60 \%$ under all cutting conditions. The values of surface roughness $(\mathrm{Ra})$ under MQL are smaller and do not change much with respect to the cutting speeds or the feeds.

Kamata and Obikawa, 2007 experimentally investigated high speed turning of Inconel-718 with different coated tools using the MQL technique and made a comparison between dry, wet and MQL techniques with regard to tool life and surface finish as shown in Fig. 3(a) and (b). The surface finish and tool life attained using MQL was found to be better than that in the wet and the dry machining for differently coated cutting tools. In another study Hadad and Sadeghi, 2013 found that among all the three types of turning (wet, dry and MQL) of AISI 4140 alloy steel, MQL produced the best surface quality for the entire range of depth of cut. They also noticed that minimum cutting force was required to perform turning operation with the MQL technique as compared to dry and wet turning for the entire depth of cut values. The performance of MQL technique in different machining processes offers encouraging results in terms of cost, performance and environmental related issues especially when vegetable oil-based lubricant is used as the base oil. MQL technique using vegetable oil based lubricant in any machining processes offers the best alternative in combating the environmental problems or challenges posed by mineral oil based lubricants (Lawal et al., 2013). On other hand the Vegetable based cutting fluids (VBCFs) with extreme pressure (EP) additives displayed a lower coefficient of friction, equivalent scuffing load capacity and better pitting resistance in the cutting zone in comparison to other types of cutting fluids (CFs) (Centin et al., 2011). 
a

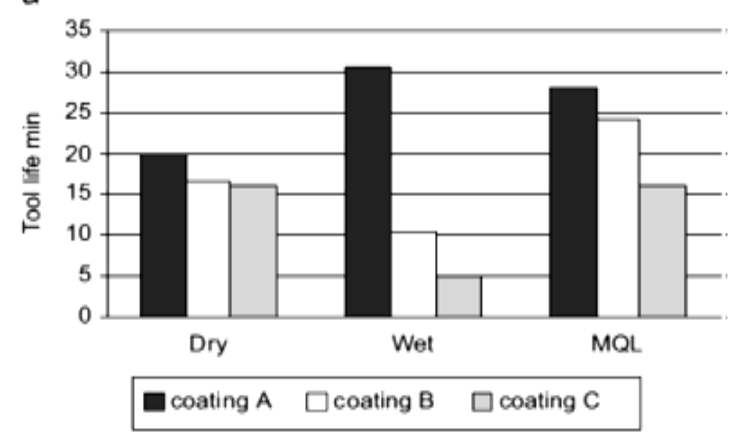

b

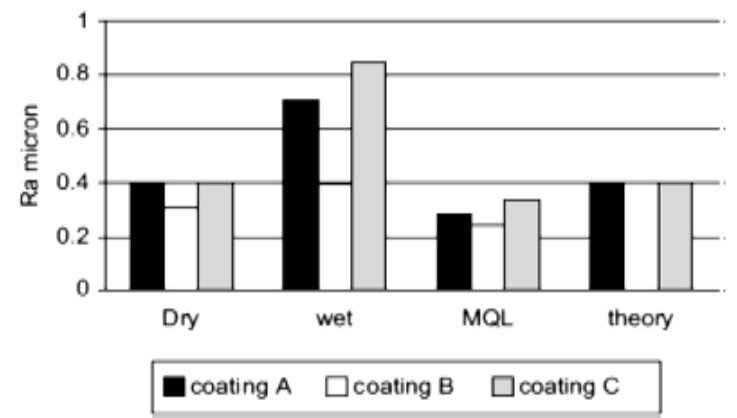

Fig. 3 Tool life and surface finishes in dry, wet and MQL machining for three different coated tools (Kamata and Obikawa, 2007)

While the MQL/NDM method aiming at reducing the usage of cutting fluids, the other branch of research has been dedicated to boost the performance of cutting fluid through modification or enhancing tribological properties, among which nano-fluids with the addition of nano-particles are over- whelmed (Chan et al., 2013).Among various techniques to reduce full usage of metal working fluids (MWF), nano-fluid minimum quantity lubrication (MQL) is an environment-friendly one, which has been recently introduced. Nano-fluid is a fluid containing nano-particles such as carbon nano-tube $(\mathrm{CNT}), \mathrm{C}_{60}, \mathrm{TiO}_{2}, \mathrm{Al}_{2} \mathrm{O}_{3}, \mathrm{MoS}_{2}$, diamond and so forth. In a nano-fluid MQL, the nanofluid is supplied to the machining area as a form of mist mixed with highly pressurized compressed air through a nozzle. Nanoparticles are an excellent media to increase the thermal conductivity of the base fluid. Besides, nano-particles significantly enhance tribological and wear characteristics (Nam et al., 2011).

\section{MQL TECHNIQUE USING VEGETABLE OIL - LUBRICANT}

Vegetable oils are being investigated as a potential source of environmentally favourable lubricants due to a combination of biodegradability, renewability and excellent lubrication performance (Fox and Stachowiak, 2007). Compared to mineral oil, vegetable oil can even enhance the cutting performance, extend tool life and improve the surface finishing according to some recent analysis from industry. Although, they have many environmental benefits, vegetable oils are more susceptible to degradation by oxidation or hydrolytic reactions. This is a drawback in vegetable oil-based cutting fluids (Alves andOliveira,2008).
On other side vegetable oils have a higher flash point, which reduces smoke formation and fire hazard. A higher flash point allows the use of cutting fluid under high temperature conditions (Kuram et al., 2013). In conclusion, vegetable oil-based grinding fluid not only conforms to the environmental and health requirements of environment friendly manufacturing but also satisfies the requirements of lubrication properties (Shashidhara and Jayaram, 2010).

Rahim and Sasahara, 2011 investigated for lubrication behavior of palm oil using MQL in a high speed drilling of Ti-6Al-4V. In this study, synthetic ester using MQL, air blow and flood conditions were used for comparison purposes. The palm oil and synthetic ester demon- strated a comparable performance with the flood conditions and palm oil performed better than synthetic ester on the cutting forces, temperature, power and specific cutting energy. In another study Khan and Dhar, 2006 studied for performance of vegetable based cutting fluids (VBCFs) using MQL on cutting force, tool wear, cutting heat, dimensional deviations and surface roughness in turning. They found that VBCFs with MQL depended on cutting speed and feed rate decreased with tool wear in the range of $5-12 \%$ with respect to dry cutting. MQL increased tool life and provided a better surface finish as compared to dry cutting. Cetin et al., 2011 carried out an experiment about the variation of surface roughness, cutting and feed forces during machining of AISI 304 L austenitic steel with sunflower, canola, semi synthetic and mineral based lubricating oils. It was observed that canola oil and sunflower provided the best result in terms of surface roughness values respectively. Whereas, both semi synthetic and mineral based oil failed to give surface finish better as compared to vegetable oils. Other than this, vegetable oils also outperformed both the other oils in terms of cutting and feed forces.Abdalla and Patel, 2006 evaluated the performance commercial and natural VBCFs such as coconut, sunflower, palm olive and rapeseed oils for machining of stainless steels and aerospace-grade titanium alloys. They revealed that low friction values were found for VBCFs in tribological studies and the naturally derived fluid was better for stainless steels and titanium alloys machining process.

\section{ROLE OF NANO-PARTICLES UNDER MQL TECHNIQUE}

Nano-fluids are advanced and functionalized fluids that are designed by adding nano-sized solid particles in low to moderate volumetric fractions to a base fluid (Chandrasekar et al., 2012). Most common nano-particle includes the oxide, carbide, nitride of metals and non-metals and carbon nano-tubes (CNT) (Setti et al., 2015). Recent experiments have also demonstrated that nano-fluids with minimum quantity lubrication technique have attractive properties for machining.

Nam et al., 2011 studied the characterization of the microdrilling process with the nano-fluid minimum quantity lubrication (MQL) atthe spindle speed, feed rate and drilling 
depth $(60,000 \mathrm{rpm}, 50 \mathrm{~mm} / \mathrm{min}$ and $0.4 \mathrm{~mm})$ respectively. The size of the nano-diamond particles was $30 \mathrm{~nm}$. The experimental results indicated that the nano-fluid MQL significantly increases the number of drilled holes and reduces the drilling torques and thrust forces. In addition, the nano-fluid MQL effectively eliminates remaining chips and burrs to enhance the quality of drilled holes. Ozcelik et al., 2011 studied the performances of both new developed environmental friendly vegetables based cutting fluids (refined sunflower and canola oils) including different percentage of extreme pressure (EP approximately 1500 $\mathrm{N} / \mathrm{mm}^{2}$ ) additive and two commercial cutting fluids (semisynthetic and mineral cutting fluids) in turning processes. The results indicated that the canola based cutting fluids (CCF-II) with $8 \%$ and $12 \%$ of EP additives gave higher surface quality performance than sunflower based cutting fluids (SCF-II) with $8 \%$ and $12 \%$ of EP additives, which was related to the higher lubrication property of CCF-II. But commercial semi-synthetic cutting fluid (CSSCF) gave the best performance in terms of cutting forces. It was also noted that commercial mineral based cutting fluid (CMCF) and commercial semi-synthetic cutting fluid (CSSCF) can be replaced by the vegetable based cutting fluids (VBCFs), thus reducing the occupational health risks associated with petroleum oil based cutting fluids (CFs) and reducing the waste treatment costs due to their inherently higher biodegradability.

In another study Zhang et al., 2015stated that the experimental evaluation of $\mathrm{MoS}_{2}$ nano-particles in jet MQL grinding with different types of vegetable oil as base oil. It was observed that the palm oil-based nano-fluids added with $\mathrm{MoS}_{2}$ nano-particles produce the best lubricating property in the nano-particle jet MQL condition as compared with other vegetable oils (liquid paraffin, soybean oil and rapeseed oil). This is because of the high saturated fatty acid and high film-forming property of carboxyl groups in palm oil. Talib and Rahim, 2018 evaluatedthe turning performances of modified jatropha oils (MJOs), with and without hBN particles, were investigated in comparison with synthetic ester. It was observed that modified jatropha oil with $\mathrm{hBN}$ particles $(0.05 \mathrm{wt} \%$ concentration)significantlyreduce the cutting force,cutting temperature and surface roughness, as well as prolonging toollife, in terms of cutting length by $9 \%, 8 \%, 8 \%$ and $78 \%$, respectively. Because the addition of $\mathrm{hBN}$ particles caused a lubrication film to be developed, which is protected the contact surfaces, resulting in reduced friction and thus, lower cutting forces as shown in Fig. 4. This reflected the ability of $0.05 \mathrm{wt} \%$ of $\mathrm{hBN}$ particles added, to reduce the cutting forces, due to the direct effects of rolling mechanism. The hBN particles rolled between contact surfaces of tool and workpiece, converting sliding friction to rolling friction, made possible by the lubricant flow between bearing elements.However, the excessive amount of hBN particles $(>0.05 \mathrm{wt} \%)$ causedparticle agglomeration, leading to poor machining performances, interms of cutting force, cutting temperature and surface roughness.

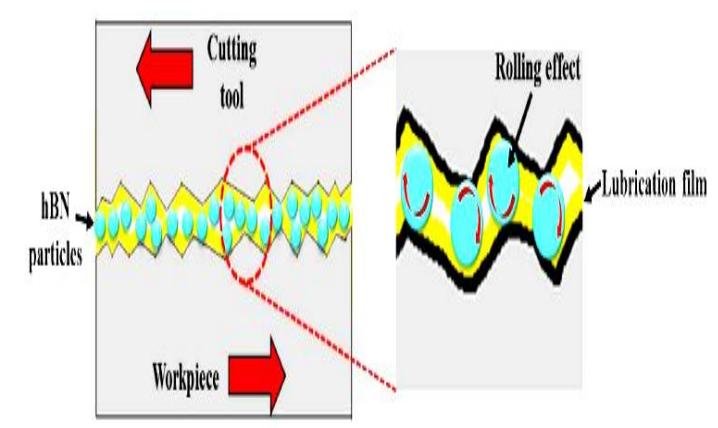

Fig. 4 Schematic diagram of contact surfaces with the presence of lubricant and hBN particles with 0.05 wt\% concentrations (Talib and Rahim, 2018)

\section{CONCLUSION}

This paper has been reviewed the application of mineral oils, vegetable oils and nanofluid-based cutting fluids with the help of MQL technique during various machining processes. The literature suggested that the green manufacturing methods such as vegetable-based cutting fluids, nanofluid-based cutting fluids etc. The outcomes from this literature are summarized as follow

1. MQL has emerged as a superior technique which minimized the ecological and biological problem caused by the rampant use of metal working fluids. Machining with the minimum volume of fluid provided results equivalent or better than conventional flood cooling. MQL successfully reduced the cutting forces, surface roughness and cutting temperature in machining operations such as turning, milling, drilling and grinding.

2. Other hand to reduce the effect of mineral based cutting fluid replaced by vegetable based oil using MQL technique which is good approach to make the machining environmental friendly. Vegetable based cutting fluids are not only biodegradable, renewable, and less toxic, but also they have been found to improve the machining performance.

3. Heat generated during machining is critical in terms of workpiece quality, as it directly affects product quality at the tool-workpiece interface. In addition of nanoparticles in the base fluid increases heat transfer rate and also reduces coefficient of friction by forming thin tribofilm on the ground surface. The product quality also improves by the using of nanolubricants due to the rolling action of nano-particles at the tool-workpiece interface, which significantly reduces cutting force.

\section{REFERENCES}

[1] A.D. Jayal, A.K. Balaji, A. Gaul and Dean R. Lillquist, "Machining performance and health effects of cutting fluid application in drilling of A390 cast aluminium alloy," J Manuf Process, Vol. 2, pp. 137146, 2007.

[2] B. Ozcelik, E. Kuram, M.H. Cetin and E. Demirbas, "Experimental investigations of vegetable based cutting fluids with extreme pressure 
during turning of AISI 304L," Tribol Int, Vol.44, pp.1864-1871, 2011.

[3] B. Ozcelik, E. Kuram, M.H. Cetin and E. Demirbas, "Experimental investigations of vegetable based cutting fluids with extreme pressure during turning of AISI 304L," Tribol Int, Vol.44, pp.1864-1871, 2011.

[4] C.Y. Chan, W.B. Lee and H. Wang, "Enhancement of surface finish using water-miscible nano-cutting fluid in ultra-precision turning," Int J Mach Tool Manu, Vol.73, pp.62-70, 2013.

[5] D. Carou, E.M. Rubio, C.H. Lauro and J.P. Davim, "Experimental investigation on surface finish during intermittent turning of UNS M11917 magnesium alloy under dry and near dry machining conditions," Measurement, Vol.56, pp.136-154, 2014.

[6] D. Nageswara Rao and P. Vamsi Krishna, "The influence of solid lubricant particle size on machining parameters in turning," Int $J$ Mach Tool Manu, Vol.48 (2008), pp.107-111,

[7] D. Setti, M.k. Sinha, S. Ghosh and P. Venkateswara Rao, "Performance evaluation of Ti-6Al-4V grinding using chipformation and coefficient of friction under the influence of nanofluids," Int $J$ Mach Tools Manuf, Vol.88, pp. 237-248, 2015.

[8] D.G. Thakur, B. Ramamoorthy and L. Vijayaraghavan, "Machinability investigationof Inconel 718 in high-speed turning," Int J Adv Manuf Tech, Vol.45, pp.421-429, 2009.

[9] D.U. Braga, A.E. Diniz, G.W.A. Miranda and N.L. Coppini, "Using a minimum quantity of lubricant (MQL) and a diamond coated tool in the drilling of aluminium-silicon alloys," J Mater Process Tech, Vol.122, pp.127-138, 2002.

[10] E. A. Rahim and H. Sasahara, "A study of the effect of palm oil as MQL lubricant on high speed drilling of titanium alloy," Tribol Int Vol.44, pp.309-317, 2011.

[11] E. Kuram, B. Ozcelik, M. Bayramoglu, E. Demirbas and B.T. Simsek, "Optimization of cutting fluids and cutting parameters during end milling by using D-optimal design of experiments," J Clean Prod, Vol.42, pp.159-166, 2013.

[12] E. Vazquez, J. Gomar, J. Ciurana and C.A. Rodriguez, "Analyzing effects of cooling and lubrication conditions in micro milling of Ti6Al4V," J Clean Prod, Vol.87, pp.906-913, 2015.

[13] F. Itoigawa, D. Takeuchi, T. Nakamura and T.H.C. Childs, "Experimental study on lubrication mechanism in mql intermittent cutting process," Mach Sci Tech, Vol.11, pp.355-365, 2007.

[14] F. Rabiei, A.R. Rahimi, M.J. Hadad and M. Ashrafijou, "Performance improvement of minimum quantity lubrication (MQL) technique in surface grinding by modeling and optimization," J Clean Prod, Vol.86, pp. 447-460, 2015.

[15] F.V. Diaz, R.E. Bolmaro, A.P.M. Guidobono and E.F. Girini, "Determination of Residual Stresses in high speed milled aluminium alloys using a method of indent pairs," Exp Mech Vol.50, pp.205-215, 2010.

[16] H. Mohammadjafar and S. Banafsheh, "Minimum quantity lubrication-MQL turning of AISI 4140 steel alloy," J Clean Prod Vol.54, pp.332-343, 2013.

[17] H.S. Abdalla and S. Patel, "The performance and oxidation stability of sustainable metalworking fluid derived from vegetable extracts," Int J Eng Manuf, Vol. 220, pp.2027-2040, 2006.
[18] J. Sharma and B.S. Sidhu, "Investigation of effects of dry and near dry machining on AISI D2 steel using vegetable oil," J Clean Prod, Vol.66, pp. 619-623, 2014.

[19] Jung Soo Nam, Pil-Ho Lee and Sang Won Lee, "Experimental characterization of micro-drilling process using nanofluid minimum quantity lubrication," Int J Mach Tool Manu, Vol.51, pp. 649-652, 2011.

[20] K. Weinert, I. Inasaki, J.W. Sutherland and T. Wakabayashi, "Dry machining and minimum quantity lubrication," Annals of CIRP Manuf Tech, Vol.53, pp. 511-537, 2004.

[21] K.M. Li and S.Y. Chou, "Experimental evaluation of minimum quantity lubrication in near micro-milling," $J$ Mater Process Tech Vol.210, pp.2163-2170, 2010.

[22] M. Chandrasekar, S. Suresh and T. Senthilkumar, "Mechanisms proposed through experimental investigations on thermophysical properties and forced convective heat transfer characteristics of various nanofluids - A review," Renew Sust Energ Rev, Vol.16, pp.3917-3938, 2012.

[23] M. Khan and N. Dhar, "Performance evaluation of minimum quantity lubrication by vegetable oil in terms of cutting force, cutting zone temperature, tool wear, job dimension and surface finish in turning AISI-1060 steel," J Zhejiang Univ Sci, Vol.7, pp.1790-1799, 2006.

[24] M. Sayuti, A. A.D. Sarhan and F. Salem, "Novel uses of $\mathrm{SiO}_{2}$ nanolubrication system in hard turning process of hardened steel AISI4140 for less tool wear, surface roughness and oil consumption," J Clean Prod, Vol.67, pp.265-276, 2014.

[25] M. Sayuti, A.A.D. Sarhan, T. Tanaka, M. Hamdi and Y. Saito, "Cutting force reduction and surface quality improvement in machining of aerospace duralumin AL-2017-T4 using carbon onion nanolubrication system," Int J Adv Manuf Tech, Vol.65, pp.1493500, 2013.

[26] M.H. Cetin, B. Ozcelik, E. Kuram and E. Demirbas, "Evaluation of vegetable based cutting fluids with extreme pressure and cuttingparameters in turning of AISI 304L by Taguchi method," $J$ Clean Prod, Vol.19, pp. 2049-2056, 2011.

[27] N. Talib and E.A. Rahim, "Performance of modified jatropha oil in combination with hexagonal boron nitride particles as a bio-based lubricant for green machining," Tribol Int, Vol.118, pp.89-104, 2018.

[28] N.J. Fox and G.W. Stachowiak, "Vegetable oil-based lubricants-a review of oxidation," Tribol Int, Vol.40, pp.1035-1046, 2007.

[29] N.R. Dhar, M. Kamruzzaman and M. Ahmed, "Effect of minimum quantity lubrication (MQL) on tool wear and surface roughness in turning AISI-4340 steel," J Mater Process Tech, Vol.172, pp.299304, 2006.

[30] S.A. Lawal, I.A. Choudhury, Y. Nukman, "A critical assessment of lubrication techniques in machining processes: a case for minimum quantity lubrication using vegetable oil-based lubricant," J Clean Prod, Vol.41, pp.210-221, 2013.

[31] S.M. Alves and J.F.G. Oliveira, "Vegetable based cutting fluid-an environmental alternative to grinding process," In: 15th CIRP International Conference on Life Cycle Engineering. Syndey, pp. 664$668,2008$. 